\title{
Desempenho e digestibilidade de nutrientes em ovinos alimentados com rações contendo farelo de babaçu
}

\author{
Antônio Robson Bezerra Xenofonte ${ }^{1}$, Francisco Fernando Ramos de Carvalho ${ }^{2}$, Ângela Maria \\ Vieira Batista ${ }^{2}$, Geovergue Rodrigues de Medeiros ${ }^{3}$, Rafael de Paula Xavier de Andrade ${ }^{4}$ \\ ${ }_{1}$ Programa de Pós-Graduação da UFRPE; Escola Agrotécnica Federal do Crato, CE. \\ 2 Departamento de Zootecnia da UFRPE. \\ ${ }^{3}$ Escola Agrotécnica Federal de Codó, MA. \\ ${ }^{4}$ Graduação em Zootecnia da UFRPE.
}

RESUMO - Com o objetivo de avaliar o desempenho, o consumo voluntário e a digestibilidade dos nutrientes, foram utilizados 24 ovinos sem raça definida (SRD), machos não-castrados, com peso inicial de $20 \pm 3,25 \mathrm{~kg}$ e 4,6 \pm 0,8 meses de idade. Os animais foram mantidos em confinamento e alimentados com dietas com farelo de babaçu (0, 10, 20 e 30\%) em substituição ao feno de capim-colonião. As dietas, isoprotéicas e isoenergéticas, foram fornecidas em forma de ração completa. Utilizou-se um delineamento em blocos casualizados, com quatro tratamentos e seis repetições. O consumo de matéria seca foi influenciado pela inclusão do farelo de babaçu na dieta e apresentou redução de $302 \mathrm{~g} / \mathrm{dia}$ a cada $10 \%$ de participação de farelo de babaçu. A ingestão dos nutrientes e o desempenho foram restringidos pela diminuição do consumo de matéria seca. A inclusão do farelo de babaçu reduziu linearmente o ganho de peso dos animais. A digestibilidade dos nutrientes foi influenciada pelos níveis de farelo de babaçu, mas esse aumento está associado às reduções na ingestão de matéria seca. O farelo de babaçu, ao ser utilizado como alternativa de alimento para cordeiros em crescimento, compromete o consumo de alimentos e o ganho de peso dos animais.

Palavras-chave: alimento alternativo, cordeiros, ganho de peso, subproduto

\section{Performance and nutrient digestibility on lambs fed diets containing different levels of babassu meal}

\begin{abstract}
With the objective to evaluate the performance, voluntary intake and nutrient digestibilities, 24 NDB (no defined breed), non castrated male lambs with $20 \pm 3.25 \mathrm{BW}$ initial and $4.6 \pm 0.8$ months old were used. Animals were kept in feedlot and fed diets with babassu meal $(0,10,20$ and 30\%) in substitution to Panicum maximum Jack hay. The diets, isoprotein and isonitrogenous, were fed in a complete mix ration. A completely blocks randomized design, with four treatments and six replicates was used. The dry matter intake was influenced by the inclusion of babassu meal in the diet and presented a reduction of $302 \mathrm{~g}$ /day for each $10 \%$ of babassu meal inclusion. Nutrient intake and performance were limited by the decrease of dry matter intake. The inclusion of babassu meal caused a linear decrease on average daily gain of lambs. Nutrient digestibility was influenced by inclusion of babassu meal in the diet, but this increase was a result of the reduction on dry matter intake. Babassu meal, used as an alternative feed for growing sheep, affect nutrient intake and weight gain of the animals.
\end{abstract}

Key Words: alternative feed, by-product, sheep, weight gain

\section{Introdução}

O crescente consumo de carne ovina no Brasil tem ampliado as fronteiras de criação de ovinos e, também, levado à necessidade de incrementar o desempenho produtivo dos rebanhos. Assim, tem-se procurado alternativas alimentares regionais que possam reduzir o custo de produção desses animais.
É importante na avaliação de um alimento o seu consumo voluntário. Na estimativa do consumo, devem ser consideradas as limitações relativas ao animal, ao alimento e as condições de alimentação, uma vez que o desempenho é função do consumo de matéria seca digestível (Mertens, 1994).

Outra característica importante na avaliação de um alimento é a sua digestibilidade, que, associada ao consumo, contribuirá para o desempenho do animal. 
A terminação de cordeiros em sistemas de confinamento não é prática usual entre os ovinocultores brasileiros, que tradicionalmente adotam o sistema extensivo de produção. Todavia, em virtude das perspectivas de mercado, faz-se necessário intensificar processos de terminação de cordeiros para garantir a produção de animais precoces, que resulta em carcaças de elevada qualidade e retorno mais rápido do capital investido.

De acordo com Siqueira (1993), uma grande vantagem do confinamento em relação à terminação em pastagem e a redução das infestações endoparasitárias, que diminui a mortalidade dos animais e resulta em maiores ganhos de peso diário nos cordeiros confinados. Oliveira et al. (2002) comentam que as maiores desvantagens do confinamento são os altos custos de produção, principalmente com alimentação, que constitui fator determinante no aspecto financeiro.

O uso de resíduos agroindustriais na alimentação animal pode trazer desempenhos satisfatórios na produção de carne ovina e, segundo Furusho-Garcia et al. (2000), assume grande valor, principalmente, na terminação em confinamento, quando o objetivo é a redução do custo de produção.

São poucos os trabalhos encontrados na literatura com farelo de babaçu na alimentação animal, especialmente de ovinos. O farelo de babaçu é classificado como fonte protéica (Benedett \& Spers, 1995); a variação na sua composição e o processamento são fatores que influenciam sua composição final. No estado do Piauí, algumas indústrias demonstraram que o farelo de babaçu possui 14 a $24 \%$ de proteína bruta e mais de $50 \%$ de fibra em detergente neutro.

Souza Jr. (2003), em experimento com ovinos Santa Inês recebendo dietas com farelo de babaçu (0, 10, 20 e 30\% na matéria seca), observou redução na ingestão de matéria seca.

Este trabalho foi realizado com o objetivo de avaliar o desempenho e a digestibilidade de nutrientes em cordeiros sem raça definida (SRD) alimentados com dietas contendo farelo de babaçu.

\section{Material e Métodos}

O trabalho foi desenvolvido no setor de ovinocaprinocultura da Escola Agrotécnica Federal, localizada na cidade de Crato-CE, microrregião do Cariri e mesorregião do Araripe, com latitude $7^{\circ} 14^{\prime \prime}$ e longitude $39^{\circ} 14^{\prime \prime}$ em relação a Greenwich e altitude de $450 \mathrm{~m}$. O clima é quente, seco e a temperatura média do ar, de $26^{\circ} \mathrm{C}$ (IBGE, 2006).

Foram utilizados 24 cordeiros sem raça definida (SRPD), machos, não-castrados, com 4,6 $\pm 0,8$ meses de idade e peso inicial de $20 \pm 3,25 \mathrm{~kg}$ confinados em baias individuais com $1,20 \mathrm{~m}^{2}(0,60 \times 2,0 \mathrm{~m})$ providas de comedouro e bebedouro. Após pesagem, identificação e tratamento contra ecto e endoparasitos, os animais foram vacinados contra clostridiose e recebendo, ainda, uma dose de complexo vitamínico.

Como tratamentos, foram avaliados na dieta quatro níveis de farelo de babaçu (0, 10, 20 e 30\%). A dieta foi fornecida na forma de ração completa, nos horários de $8 \mathrm{~h} 30$ e 15h30, e formulada para promover ganhos de peso de 150 g/dia, de acordo com o NRC (1985). O período experimental teve duração de 60 dias, incluindo 10 dias para adaptação às dietas, às instalações e aos manejos diários.

No período de adaptação, os animais receberam rações em quantidade correspondente a $4 \%$ do seu peso vivo até estabilizarem o consumo voluntário. Durante o período de coleta de dados, esta relação de $4 \%$ do peso vivo foi mantida, porém foi permitida sobra de $10 \%$.

As dietas experimentais (Tabelas 1 e 2) foram constituídas de raspa de mandioca, farelo de soja, milho moído, farelo de babaçu, feno de capim-colonião (Panicum maximum Jack), uréia e calcário. O cálculo de nutrientes digestíveis totais para formulação das rações foi feito de acordo com Valadares Filho et al. (2006).

Durante o processamento, todos os ingredientes foram moídos em peneiras de crivo de $5 \mathrm{~mm}$ para maior homogeneização das rações e redução da seleção pelos animais. Durante o período experimental, os animais receberam água limpa e sal mineral à vontade.

Os alimentos e as sobras, incluindo o período do ensaio de digestibilidade, foram pesados diariamente para cálculo do consumo diário e da conversão alimentar (CA). Amostras de $50 \mathrm{~g} / \mathrm{animal} / \mathrm{dia}$ foram coletadas e posteriormente analisadas quanto aos teores de matéria seca (MS), matéria mineral (MM), nitrogênio total (NT) e extrato etéreo (EE), segundo metodologia descrita por Silva \& Queiroz (2002). O teor de proteína bruta (PB) foi obtido pelo produto entre o teor de nitrogênio total (NT) e o fator 6,25 . Os teores de fibra em detergente neutro e fibra em detergente ácido foram determinados segundo metodologia de Van Soest et al. (1991).

Para estimativa dos carboidratos totais (CT), foi usada a equação proposta por Sniffen et al. (1992), em que $\mathrm{CT}=100-(\% \mathrm{~PB}+\% \mathrm{EE}+\%$ matéria mineral $)$. A equação CNF $(\%)=\%$ CT $-\% F D N p$, preconizada por Hall et al. (1999), foi utilizada para estimar os carboidratos não-fibrosos (CNF), considerando o teor de FDN corrigida para proteína e o NDT informado por Valadares Filho et al. (2006).

Foram avaliados os consumos de matéria seca (MS), proteína bruta (PB), fibra em detergente neutro (FDN), fibra em detergente ácido (FDA), matéria orgânica (MO) e matéria 
Tabela 1 - Composição dos ingredientes (\%MS)

\begin{tabular}{|c|c|c|c|c|c|c|c|c|c|c|c|}
\hline Ingrediente & MO & MS & MM & PB & $\mathrm{EE}$ & FDN & $\mathrm{FDN}_{\mathrm{P}}{ }^{1}$ & FDA & $\mathrm{CNF}$ & $\mathrm{NDT}^{2}$ & $\mathrm{CT}$ \\
\hline Farelo de soja & 95,90 & 89,81 & 4,10 & 52,02 & 1,62 & 18,29 & 15,32 & 10,11 & 26,94 & 81,54 & 42,26 \\
\hline Farelo de babaçu & 98,40 & 90,33 & 1,60 & 20,66 & 5,81 & 39,56 & 38,58 & 18,75 & 33,35 & 49,38 & 71,93 \\
\hline Raspa de mandioca & 99,53 & 87,41 & 0,47 & 4,78 & 0,50 & 24,34 & 23,85 & 5,85 & 70,00 & 72,27 & 94,25 \\
\hline Uréia & 0 & 100 & 0 & 280 & 0 & 0 & 0 & 0 & 0 & 0 & 0 \\
\hline Calcário & 100 & 100 & 0 & 0 & 0 & 0 & 0 & 0 & 0 & 0 & 0 \\
\hline
\end{tabular}

1 Valadares Filho (2002).

2 Estimado pela equação de Weiss (1999).

Tabela 2 - Composição das dietas experimentais (\%MS)

\begin{tabular}{lcccc}
\hline Ingrediente & \multicolumn{4}{c}{ Nível de babaçu (\%) } \\
\cline { 2 - 5 } & 0 & 10 & 20 & 30 \\
\hline Grão de milho moído & 32,20 & 38,00 & 41,00 & 42,20 \\
Farelo de soja & 16,00 & 13,00 & 11,00 & 8,00 \\
Feno de capim-colonião & 30,00 & 25,00 & 18,20 & 10,00 \\
Farelo de babaçu & 0,00 & 10,00 & 20,00 & 30,00 \\
Raspa de mandioca & 20,00 & 12,20 & 8,00 & 8,00 \\
Uréia & 0,80 & 0,80 & 0,80 & 0,80 \\
Calcário calcítico & 1,00 & 1,00 & 1,00 & 1,00 \\
\hline Nutriente & & & & \\
\hline Matéria seca & 89,01 & 89,17 & 89,28 & 89,31 \\
Matéria orgânica & 96,08 & 96,04 & 96,89 & 97,47 \\
Proteína bruta & 16,92 & 17,27 & 17,90 & 17,93 \\
Extrato etéreo & 2,31 & 2,93 & 3,43 & 3,83 \\
Fibra em detergente neutro & 36,79 & 36,15 & 34,63 & 32,52 \\
FDN corrigida para proteína & 35,71 & 35,07 & 33,53 & 31,44 \\
Fibra em detergente ácido & 19,29 & 18,25 & 16,49 & 14,08 \\
Carboidratos totais & 78,09 & 77,49 & 76,80 & 76,95 \\
Carboidratos não-fibrosos & 42,38 & 42,42 & 43,28 & 45,51 \\
Matéria mineral & 3,12 & 2,76 & 2,31 & 1,73 \\
Nutrientes digestíveis totais & 71,18 & 70,50 & 69,85 & 69,13 \\
\hline
\end{tabular}

mineral (MM), o peso vivo inicial (PVI), o peso vivo final (PVF), o peso vivo ao abate (PVA), o ganho de peso diário (GPD) e a conversão alimentar (CA).

O ganho de peso diário foi registrado por meio de pesagens realizadas a cada dez dias, após jejum de alimentos sólidos de 18 horas.

Para o ensaio de digestibilidade, foram utilizados os últimos sete dias do período experimental do ensaio de desempenho. Nesse período, foram colhidas amostras de fezes, diretamente na ampola retal dos animais, e amostras de alimentos e sobras.

Amostras de fezes, alimentos e sobras foram incubadas no rúmen de um bubalino macho adulto (mestiço castrado) durante 144 horas, em sacos tipo ANKON, segundo metodologia descrita por Berchielle et al.(2000), porém com quanto à incubação in situ. A quantidade da amostra incubada foi de $1,0 \mathrm{~g}$ para alimentos concentrados e $0,5 \mathrm{~g}$ para feno, fezes e sobras. O material remanescente da incubação foi submetido à extração com detergente ácido, cujo resíduo foi considerado FDAi. As análises laboratoriais foram realizadas no Laboratório de Nutrição Animal do Departamento de Zootecnia da UFRPE.

Foram calculados os coeficientes de digestibilidade da matéria seca, matéria orgânica, proteína bruta, fibra em detergente neutro e extrato etéreo.

O delineamento experimental utilizado foi o de blocos casualizados, com quatro tratamentos e seis repetições. Os blocos foram formados pelos animais, de acordo com o peso inicial. Além da análise de variância, foi realizada análise de regressão, das variáveis considerando os níveis de farelo de babaçu nas dietas.

Os critérios utilizados para a escolha das equações foram o comportamento biológico, o coeficiente de determinação $\left(\mathrm{R}^{2}\right)$, calculado como a relação entre a soma do quadrado da regressão e a soma do quadrado total, e a significância para os parâmetros de regressão, obtida pelo teste t, nos níveis de 1 e 5\% de probabilidade.

As análises estatísticas foram realizadas pelo pacote estatístico SAEG (UFV, 2001).

\section{Resultados e Discussão}

Houve efeito linear decrescente $(\mathrm{P}<0,05)$ dos níveis de farelo de babaçu sobre o consumo de matéria seca em g/dia (Tabela 3). As médias de consumo de MS foram de 1.377,00; 975,70; 596,70 e 448,90 g/dia, para ovinos SPRD alimentados, respectivamente, com as dietas contendo 0, 10, 20 e $30 \%$ de farelo de babaçu. Comportamento semelhante foi observado por Sousa Jr. (2003), em ovinos Santa Inês alimentados também com dietas contendo 0, 10, 20 e $30 \%$ de farelo de babaçu: $1.248,48 ; 1.234,01 ; 1.197,99$ e $1.025,88 \mathrm{~g} /$ dia.

Os consumos de matéria seca expressos em porcentagem do peso vivo foram 5,37 ; 3,63; 2,79 e 2,72\% nos níveis de $0,10,20$ e $30 \%$ de farelo de babaçu, o que indica resposta quadrática $(\mathrm{P}<0,05)$, com ponto de mínima 25,56\% de participação do farelo de babaçu. 
O consumo de matéria seca por unidade do tamanho metabólico acompanhou a mesma resposta quadrática $(\mathrm{P}<0,05)$ do consumo de matéria seca em relação ao peso vivo, com ponto de mínima 28,17\%, ou seja, praticamente uma resposta linear aos níveis de farelo de babaçu estudados. De acordo com o NRC (1985), o consumo diário de matéria seca/ kg de $\mathrm{PV}^{0,75}$, para o tamanho dos animais deste experimento, deve ser de $100 \mathrm{~g} / \mathrm{kg}$ de $\mathrm{PV}^{0,75}$, valor superior aos encontrados neste trabalho com a inclusão do farelo de babaçu nas dietas dos cordeiros em confinamento.

Barros et al. (1994), em experimento com ovinos Santa Inês x SPRD, obtiveram valores médios de 77,30; 79,20; 88,80 e 70,30 g de $\mathrm{MS} / \mathrm{kg}$ de $\mathrm{PV}^{0,75}$, ao fornecerem dietas com 15; 30; 45 e 60\% de concentrado, respectivamente.

Se considerada a composição química das dietas, a redução de consumo não pode ser explicada pelos teores de fibra, proteína, minerais e nutrientes digestíveis totais. Algum fator não identificado, talvez um fator antinutricional associado ao farelo de babaçu, pode ter contribuído para interferir no consumo de alimentos pelos animais. Também não houve possibilidade de seleção pelos animais, uma vez que as dietas estavam homogeneizadas e moídas finamente.

A resposta para o consumo de matéria orgânica, proteína bruta, extrato etéreo, fibra em detergente neutro, fibra em detergente ácido, carboidratos totais, carboidratos não-fibrosos e nutrientes digestíveis totais foi linear $(P<0,05)$ e pode ser explicada pela redução do consumo de matéria seca.

A ingestão de proteína foi reduzida $(\mathrm{P}<0,05)$ em $56,2 \mathrm{~g} /$ dia para cada $10 \%$ de participação do farelo de babaçu. Segundo o NRC (1985), o consumo de proteína bruta deve ser de 160 a 191g/dia para atender às exigências dos animais utilizados neste experimento. Todavia, nas dietas com 20 e $30 \%$ de farelo de babaçu, os consumos de proteína bruta foram de 106,80 e $80,49 \mathrm{~g} /$ dia, respectivamente, o que refletiu no ganho de peso dos animais. Apesar de o nível de FDN ter aumentado com a participação do farelo de babaçu, houve redução $(\mathrm{P}<0,05)$ de aproximadamente $123 \mathrm{~g} /$ dia para cada $10 \%$ no nível de participação desse alimento. Como as dietas eram homogeneizadas na hora do fornecimento, considera-se que não houve seleção pelos animais e a FDN representou 36,8; 36,2; 34,6 e 32,5\% do consumo de matéria seca, percentuais semelhantes à composição das dietas.

A ingestão média diária de FDN observada neste experimento foi inferior à encontrada por Sousa Jr. (2003), que relatou valores de 461,94; 535,80; 560,18 e 532,43 kg para os níveis de 0; 10; 20 e 30\% de farelo de babaçu, respectivamente. Segundo esse autor, o menor consumo de matéria seca esteve associado ao maior teor de FDN na dieta.

Neste trabalho, o teor de FDN não comprometeu o consumo de matéria seca, pois os teores foram, inclusive, menores com a participação do farelo de babaçu nas dietas. É indiscutível a importância da fibra das forragens para o suprimento de carboidratos utilizados como fonte de energia pelos microrganismos do rúmen para produção de ácidos graxos voláteis e, para estimulação da mastigação e ruminação, pois contribui para elevar a salivação e o tamponamento do $\mathrm{pH}$ ruminal (Cardoso et al., 2006).

Furusho-Garcia et al. (2000), trabalhando com casca de café na alimentação de ovinos, verificaram que o consumo de fibra em detergente neutro variou de 300 a $430 \mathrm{~g} / \mathrm{dia}$, valores semelhantes aos encontrado para a inclusão de $10 \%$ do farelo de babaçu. Materiais alternativos, como casca de café ou farelo de babaçu, devem ser analisados quanto a outros aspectos além da composição de proteína bruta, matéria orgânica, fibra em detergente neutro, lignina, extrato etéreo ou cinzas.

Para o cálculo dos carboidratos não-fibrosos, foram incluídos todos os carboidratos solúveis em detergente

Tabela 3 - Consumo de nutrientes em ovinos alimentados com dietas contendo farelo de babaçu

\begin{tabular}{|c|c|c|c|c|c|c|c|}
\hline Item & \multicolumn{4}{|c|}{ Nível de babaçu (\%) } & CV (\%) & Equação de regressão & $\mathrm{R}^{2}$ \\
\hline MS, g/dia & $1.377,00$ & 975,70 & 596,70 & 448,90 & 22,5 & $\hat{\mathrm{Y}}=1324,60-31,6559 * \mathrm{FB}^{\mathrm{s}}$ & 0,96 \\
\hline MS, g/kg 0,75 & 120,78 & 82,72 & 59,96 & 55,29 & 23,6 & $\hat{\hat{Y}}=120,921-4,69507 * \mathrm{FB}+0,08334009 * \mathrm{FB}^{2} \mathrm{~s}$ & 0.98 \\
\hline $\mathrm{MO}, \mathrm{g} / \mathrm{dia}$ & $1.323,00$ & 941,02 & 578,11 & 437,60 & 22,6 & $\hat{\mathrm{Y}}=1273,32-30,2146 * \mathrm{FB} \mathrm{s}$ & 0,96 \\
\hline PB, g/dia & 247,45 & 168,41 & 106,80 & 80,50 & 22,6 & $\hat{\mathrm{Y}}=235,157-5,622471^{*} \mathrm{FB}{ }^{\mathrm{s}}$ & 0,96 \\
\hline FDA, g/dia & 265,80 & 178,10 & 98,40 & 63,20 & 21,06 & $\hat{\mathrm{Y}}=254,463-6,87363^{*} \mathrm{FB} \mathrm{s}$ & 0,97 \\
\hline NDT, g/dia & 980,70 & 687,91 & 416,80 & 310,32 & 22,38 & $\hat{\hat{Y}}=941,244-22,8217 * F B s$ & 0,96 \\
\hline $\mathrm{CT}$, g/dia 1 & $1.075,80$ & 756,12 & 458,24 & 345,42 & 22,46 & $\hat{\mathrm{Y}}=1032,29-24,8920 * \mathrm{FB} \mathrm{s}$ & 0,96 \\
\hline CNF, g/dia & 583,05 & 413,92 & 258,24 & 204,30 & 22,99 & $\hat{\hat{Y}}=558,670-12,9197 * \mathrm{FB} s$ & 0,96 \\
\hline
\end{tabular}

$\mathrm{FB}=$ nível de farelo de babaçu.

${ }^{*} \mathrm{~s}=$ Significativo a 5 de probabilidade, respectivamente, pelo teste $\mathrm{t}$. 
neutro, que são facilmente fermentados pelos microrganismos do rúmen. Estima-se que o amido foi o carboidrato mais consumido da dieta, como conseqüência da utilização de mandioca e milho como fontes de energia. $\mathrm{O}$ tratamento sem farelo de babaçu apresentou ainda maior teor de alimentos ricos em amido, o que contribuiu para o maior consumo de matéria seca observado neste experimento.

Segundo Ferreira (2005), o milho, em grandes proporções nas dietas mistas de volumoso e concentrado, pode reduzir a digestibilidade e pode até provocar acidose quando a concentração de amido é elevada, ou seja, $0,333 \mathrm{~kg}$, provocando inapetência, atonia ruminal, aumento da freqüência respiratória e diarréias, fato observado em alguns animais do experimento, mas que não ocasionou redução no consumo de alimentos, pois os maiores níveis de consumo ocorreram quando fornecidas as dietas com mais amido.

Uma vez que os valores de consumo dos nutrientes ficaram abaixo dos preconizados pelo NRC (1985), pode-se afirmar que o consumo das dietas com maiores níveis de farelo de babaçu não atendeu às exigências nutricionais dos animais em experimento.

Houve efeito linear decrescente $(\mathrm{P}<0,05)$ da inclusão do farelo de babaçu sobre o peso vivo final, o peso vivo ao abate, o ganho de peso total e o ganho de peso diário (Tabela 4). Por outro lado, não foi observada influência dos níveis de farelo de babaçu sobre a conversão alimentar, que apresentou média de 8,01, valor inferior ao encontrado por Sousa Jr. (2003), que trabalhou com os mesmos níveis de farelo de babaçu, ou seja, 0, 10, 20 e 30\%, em ovinos Santa Inês em terminação.

Os ganhos de peso observados neste trabalho foram superiores aos relatados por Towsend et al. (1998), que trabalharam com níveis de casca de café $(0,10,20$ e 30\%) e verificaram ganhos de peso de 9,$10 ; 18,80 ; 14,50$ e 49,10 g/dia, respectivamente.

Para cada $10 \%$ de participação do farelo de babaçu na dieta, houve redução de 51,4 g/dia no ganho de peso dos animais. Esse resultado é explicado pela redução na ingestão de matéria seca, que limitou a ingestão de energia e proteína, além de outros nutrientes.

A resposta dos animais para o ganho de peso está associada ao consumo de matéria seca e de nutrientes. O consumo de energia (considerando o valor para NDT da Tabela 2) no tratamento sem farelo de babaçu foi suficiente para ganhos maiores que $200 \mathrm{~g} / \mathrm{dia}$, segundo recomendações do NRC (1985). Todavia, foi limitado pelo potencial de ganho de peso dos animais estudados. No nível de inclusão de $30 \%$ de farelo de babaçu, foi observado ganho de aproximadamente $50 \mathrm{~g} /$ dia. Os ganhos de peso diários nos tratamentos com 10 e $20 \%$ de farelo de babaçu estão em conformidade com o NRC (1985).

Os coeficientes de digestibilidade (Tabela 5) da matéria seca, matéria orgânica, proteína bruta e extrato etéreo

Tabela 4 - Peso vivo final (PVF), peso vivo ao abate (PVA), ganho em peso total (GPT), ganho de peso diário (GPD) e conversão alimentar (CA) em ovinos alimentados com dietas contendo farelo de babaçu

\begin{tabular}{|c|c|c|c|c|c|c|c|}
\hline \multirow[t]{2}{*}{ Item } & \multicolumn{4}{|c|}{ Nível de babaçu (\%) } & \multirow[t]{2}{*}{ CV (\%) } & \multirow[t]{2}{*}{ Equação de regressão } & \multirow[t]{2}{*}{$\mathrm{R}^{2}$} \\
\hline & 0 & 10 & 20 & 30 & & & \\
\hline PVF, kg & 30,46 & 32,15 & 24,28 & 19,62 & 10,3 & $\hat{\mathrm{Y}}=33,3627-0,429827 * \mathrm{FB} s$ & 0,93 \\
\hline PVA, kg & 29,58 & 30,0 & 22,70 & 18,64 & 11,0 & $\hat{\mathrm{Y}}=31,2288-0,398066 * \mathrm{FB} \mathrm{s}$ & 0,87 \\
\hline GPT, kg & 7,83 & 6,45 & 3,48 & 1,99 & 30,9 & $\hat{\mathrm{Y}}=8,0184-0,205676 * \mathrm{FB} \mathrm{s}$ & 0,98 \\
\hline GPD, g & 195,83 & 161,25 & 87,08 & 49,75 & 30,9 & $\hat{\mathrm{Y}}=200,460-5,14190 * \mathrm{FB} \mathrm{s}$ & 0,98 \\
\hline CA & 7,07 & 6,43 & 7,57 & 10,94 & 46,0 & $\hat{\mathrm{Y}}=8,01^{\mathrm{ns}}$ & - \\
\hline
\end{tabular}

FB = nível de farelo de babaçu.

* $\mathrm{s}=$ Significativo a $5 \%$ de probabilidade pelo teste $\mathrm{t}$

ns Não-significativo.

Tabela 5 - Coeficientes de digestibilidade de nutrientes em ovinos alimentados com dietas contendo farelo de babaçu

\begin{tabular}{|c|c|c|c|c|c|c|c|}
\hline \multirow[t]{2}{*}{ Digestibilidade (\%) } & \multicolumn{4}{|c|}{ Nível de babaçu (\%) } & \multirow[t]{2}{*}{ CV (\%) } & \multirow[t]{2}{*}{ Equação de regressão } & \multirow[t]{2}{*}{$\mathrm{R}^{2}$} \\
\hline & 0 & 10 & 20 & 30 & & & \\
\hline MS (\%) & 58,7 & 61,6 & 60,9 & 68,4 & 9,4 & $\hat{\mathrm{Y}}=58,138+0,285^{*} \mathrm{FB} s$ & 0,24 \\
\hline $\mathrm{PB}(\%)$ & 66,7 & 69,1 & 70,6 & 73,6 & 7,2 & $\hat{\mathrm{Y}}=66,709+0,219 * \mathrm{FB} \mathrm{s}$ & 0,20 \\
\hline FDN (\%) & 36,2 & 37,0 & 34,7 & 46,5 & 23,6 & $\hat{\hat{Y}}=38,6$ ns & - \\
\hline $\mathrm{EE}(\%)$ & 29,1 & 38,1 & 56,7 & 56,7 & 32,7 & $\hat{\hat{Y}}=29,940+1,015 * \mathrm{FB} s$ & 0,39 \\
\hline
\end{tabular}

* $s$ S Significativo a $5 \%$ de probabilidade pelo teste $\mathrm{t}$.

ns Não-significativo. 
aumentaram linearmente $(\mathrm{P}<0,05)$ de acordo com os níveis de farelo de babaçu. Essa resposta está associada à redução na ingestão desses nutrientes pelos animais, resultando em maior tempo de permanência desse material no trato gastrintestinal, favorecendo a digestibilidade. Os níveis de farelo de babaçu não influenciaram a digestibilidade da fibra em detergente neutro, embora o consumo dessa fração também tenha reduzido (Tabela 3), provavelmente em virtude da maior variação na digestibilidade desse componente.

\section{Conclusões}

A inclusão de farelo de babaçu em dietas para cordeiros em confinamento reduz o consumo de nutrientes e o ganho de peso dos animais. A redução na ingestão de matéria seca com a inclusão do farelo de babaçu em dietas aumenta a digestibilidade dos nutrientes.

\section{Literatura Citada}

BARROS, N.N.; FIGUEIREDO, E.A.P.; FERNANDES, F.D. et al. Ganho de peso e conversão alimentar de cordeiros cruzas no Estado do Ceará. Pesquisa Agropecuária Brasileira, v.29, p.1313-1317, 1994.

BENEDETT, E.; SPERS, E. Digestibilidade aparente do farelo de babaçu (Orbgnya sp) com bezerros de um ano de idade. Veterinária Noticia, v.1, p.19-28, 1995.

BERCHIELLI, T.T.; ANDRADE, P.; FURLAN, C.L. Avaliação de indicadores internos em ensaios de digestibilidade. Revista Brasileira de Zootecnia, v.29, p.830-833, 2000.

CARDOSO, A.R.; PIRES, C.C.; CARVALHO, C. et al. Consumo de nutrientes e desempenho de cordeiros com dietas que contêm diferentes níveis de fibras em detergente neutro. Ciência Rural, v.36, n.1, p.215-221, 2006.

FERREIRA, M.A. Palma forrageira na alimentação de bovinos leiteiros. Recife: Universidade Federal Rural de Pernambuco, 2005. 380p.

FURUSHO-GARCIA, I.F.; PEREZ, J.R.O.; TEIXEIRA, J.C. et al. Desempenho de cordeiros Texel x Bergamácia, Texel x Santa Inês e Santa inês puros, terminados em confinamento, alimentados com casca de café como parte da dieta. Revista Brasileira de Zootecnia, v.29, p.564-572, 2000.
HALL, M.B.; HOOVER, W.H.; JENNING, J.P. et al. A method for partitioning neutral detergent soluble carbohydrates. Journal Science Food Agriculture, v.79, p.2079-2086, 1999.

INSTITUTO BRASILEIRO DE GEOGRAFIA E ESTATÍSTICA IBGE. Pesquisa pecuária municipal. Disponível em: <www.ibge.gov.br> Acesso em: 5/2/2006.

MERTENS, D.R. Regulation of forage intake. In: FAHEY JR., G.C. (Ed). Forage quality, evaluation and utilization. Madison: American Society of Agronomy, 1994. p.450-493.

NATIONAL RESEARCH COUNCIL - NRC. Nutrient requirements of sheep. 6.ed. Washington, D.C.: National Academy Press, 1985. 99p.

OLIVEIRA, M.VM.; PÉREZ, J.R.O.; ALVES, E.L. et al. Avaliação da composição de cortes comerciais, componentes corporais e órgãos internos de cordeiros confinados e alimentados com dejetos de suínos. Revista Brasileira de Zootecnia, v.31, p.1459-1468, 2002.

SILVA, D.J.; QUEIROZ, A.C. Análise de alimentos: métodos químicos e biológicos. 3.ed. Viçosa, MG: Universidade Federal de Viçosa, 2002. 233p.

SIQUEIRA, E.R. Confinamento: a receita dos paulistas para engordar cordeiros. A Granja, v.49, p.12-17, 1993.

SNIFFEN, C.J.; O'CONNOR, J.D.; Van SOEST, P.J. et al. A net carbohydrate and protein system for evaluating cattle diets: II. Carbohydrate and protein availability. Journal of Animal Science, v.70, p.3562-3577, 1992.

SOUSA JR., F.A. Substituição parcial do farelo de soja e milho por farelo de babaçu na terminação de ovinos. Teresina: Universidade Federal do Piauí, 2003. 58p. Dissertação (Mestrado em Ciência Animal) - Universidade Federal do Piauí, 2003.

TOWNSEND, C.R.; MAGALHÃES, J.A.; COSTA, N.L. et al. Utilização da casca de café na alimentação de ovinos deslanados. In: REUNIÃO ANUAL DA SOCIEDADE BRASILEIRA DE ZOOTECniA, 35., 1998, Botucatu. Anais... Viçosa, MG: Sociedade Brasileira de Zootecnia, 1998. (CD-ROM).

UNIVERSIDADE FEDERAL DE VIÇOSA - UFV. SAEG - Sistema de análise estatísticas e genéticas. Viçosa. MG: 2001. 301p.

VALADARES FILHO, S.C.; MAGALHÃES, K.A.; ROCHA JR., V.R. et. al. Tabelas brasileiras de composição de alimentos para bovinos. CQBAL 2.0. 2.ed. Viçosa, MG: Suprema Gráfica Ltda, 2006. 329p.

Van SOEST, P.J.; ROBERTSON, J.B.; LEWIS, B.A. Methods for dietary fiber, neutral detergent fiber, and nonstarch polyssacarides in relation to animal nutrition. Journal Animal Science, v.74, p.3583-3597, 1991.

WEISS, W.P. Energy prediction equations for ruminant feeds. In: CORNELL NUTRITION CONFERENCE FEED MANUFACTURES, 61., 1999, Ithaca. Proceedings... Ithaca: Cornell University, 1999. p.176-185. 